\title{
The world we live in
}

the global

response to

HIV has been

an astounding

exercise that

combined

technology,

preventive

science,

biological

insight, social

understanding,

philanthropy

and dogged

global political

action mong the great mysteries of human existence, our uncertain relationship with our

environment has been a constant source of puzzlement. In the days of the flat earth, when gods and planets needed constant placation and sacrifice lest the food supply fail and fertility fall, surging infections were thought to be a further manifestation of divine displeasure - something that the deities inflicted upon the people (demos) from above (epi) to chasten and punish. Yet the Old Testament book of Leviticus shows that, thousands of years ago, the need to quarantine people with rashes or swellings "like the plague of leprosy" was recognised (Leviticus 13: 2-5), implying that humans understood from early on that they had a measure of control over infective afflictions.

The path from primitive ignorance and fear to the understanding of the microbiological cause of infection is, as the cliche runs, history. Nevertheless, we continue to fear uncontrolled epidemics, despite our heavy investment in technology to hold them at bay.

\section{Battling the threats}

At the beginning of 2003, during the early phases of the severe acute respiratory syndrome (SARS) epidemic, I saw lights burning in the windows of Ian Lipkin's microbiology laboratory at Columbia University, close to where I was working at the time, for 24 hours every day during the race to sequence the genome of the virus responsible. By May, the 29751-base genome of the Tor2 isolate had been sequenced in British Columbia and published in Science. ${ }^{1}$ Fortunately, although SARS was a serious illness, as classical epidemiological data were assembled we recognised that it had low infectivity. We had come to know the enemy - quickly and in fastidious detail - yet we still needed traditional methods to prevent its spread.

Infection retains its character of surprise. Who would have guessed the story of Helicobacter pylori and peptic ulcers? As an intern in 1966-1967, peptic ulcer meant antacids, stress and socioeconomic status, vagotomies, pyloroplasties and heroic surgery for life-threatening haematemesis. What other disorders - cancer, coronary disease - may have an infective element in their aetiology? And, like the global financial crisis of 2008, the Ebola epidemic of 2013 caught us off guard. It also reminded us of how critical the social environment and poverty, in particular, are to the formation of modern infective epidemics.

\section{Complex relationships}

In recent years, dramatic developments in our exploration of the universe of infection have led us to the human microbiome - the "organ" that has 10 times as many cells as does the whole of the rest of the human body - that inhabits our gut, skin and other

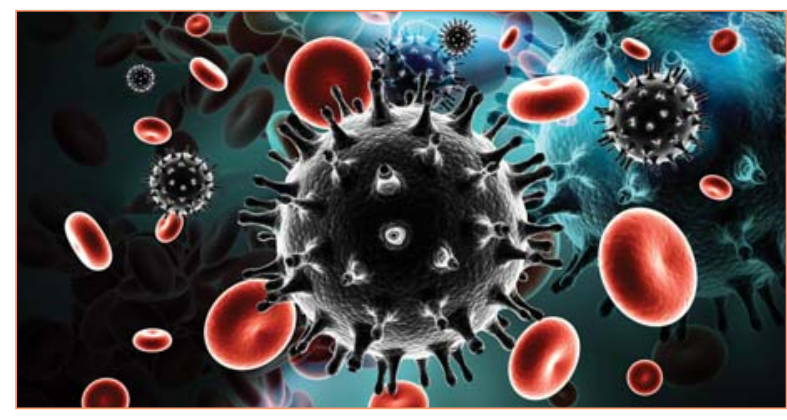

surface tissues, and about which new knowledge is coming to us daily. A 2012 Spanish study described a changing microbiome profile in human breast milk over the months after birth that involved over 700 species of microorganisms. ${ }^{2}$

I had a glimpse of the importance of the human microbiome in 1968 when working at Baiyer River in the western highlands of Papua New Guinea. We were visited by Eben Hipsley, a nutrition scientist from Canberra, who had an interest in understanding how the local Enga people, naturally muscular and fit, kept their metabolism going without eating much more than sweet potato. ${ }^{3}$ What about essential amino acids? In private conversation, Eben conjectured that their gut flora generated the molecules missing from this people's natural diet. Today's experts in this field presumably have a much better idea of Papua New Guinean nutrition, but Hipsley respected what he knew, even then, of the human microbiome. Contemporary experts now agree that while human microbiota do not fix atmospheric nitrogen, they can upgrade dietary nitrogen-containing compounds into essential amino acids. ${ }^{4}$

\section{Together, we triumph}

In terms of infection control, the global response to HIV has been an astounding exercise that combined technology, preventive science, biological insight, social understanding, philanthropy and dogged global political action. This, together with the GAVI Alliance (made up of such heavyweights as the World Health Organization, UNICEF, the World Bank, the Bill \& Melinda Gates Foundation and donor countries), the Global Fund to Fight AIDS, Tuberculosis and Malaria, and the elimination of smallpox, should surely give heart to those who doubt the value of medical research and action. Rather than lamenting what we can't do, these achievements signal what amazing things we can do together when we try.

Stephen Leeder

mja@mja.com.au

doi: 10.5694/mjal5.c0316

References are available online at www.mja.com.au. 
1 Marra MA, Jones SJM, Astell CR, et al. The genome sequence of the SARS-associated coronavirus. Science 2003; 300: 1399-1404. http://www.sciencemag.org/ content/300/5624/1399.full (accessed Feb 2015).

2 Cabrera-Rubio R, Collado MC, Laitinen K, et al. The human milk microbiome changes over lactation and is shaped by maternal weight and mode of delivery. Am J Clin Nutr 2012; 96: 544-551.

3 Hipsley EH. The relationship between energy utilization and food production: the examples of New Guinea and Australia. Canberra: Australian Institute of Anatomy, 1968.

4 Davila AM, Blachier F, Gotteland M, et al. Intestinal luminal nitrogen metabolism: role of the gut microbiota and consequences for the host. Pharmacol Res 2013; 68: 95-107. 